$\underline{\text { Three Minute Article for Parents }}$

\title{
Dengue fever in pregnancy can affect the unborn and the newborn
}

\author{
Medha Weerasekera iD, orcid.org 0000-0001-5065-1889 \\ Nimesha Chamidani Gamhewage iD, orcid/org 0000-0001-5129-4158
}

Sri Lanka Journal of Child Health, 2020; 49(3): 312

DOI: http://dx.doi.org/10.4038/sljch.v49i3.9160

(Key words: dengue fever, pregnancy, unborn, newborn)

In Sri Lanka, Dengue Fever (DF) is established as an illness seen throughout the year and affecting all ages. It is known that the Dengue virus can also be transmitted to the unborn or newborn baby from an infected pregnant mother. This type of transmission could be as high as $90 \%$. There have been several cases of Newborn DF reported in Sri Lanka, highlighting the importance of raising awareness among health staff and the general public.

An unborn baby with maternally transmitted DF may recover completely or may develop complications such as premature delivery, low birth weight and still birth. The baby's blood tests will show dengue antibodies as proof of Dengue infection before birth. DF in the mother within two weeks before delivery can be transmitted to the baby and may manifest as DF in the newborn.

Newborn babies with DF may develop fever, poor feeding, less activity and flushed skin, along with blood test results similar to older children and adults. When a mother having DF delivers her baby, the newborn should be closely observed for the above mentioned signs and laboratory markers, to determine whether the neonate is affected. NS1 antigen, a useful diagnostic test if done between 12 to 72 hours of the onset of fever, can be used in the diagnosis of neonatal DF. Newborns contracting DF may recover with minimal problems or succumb to the condition if missed or present late to hospital, just like in children or adults. It is important to reiterate that newborns too can get the more severe Dengue Haemorrhagic Fever (DHF) ${ }^{1}$.

We have reported a case of DF in a newborn, whose mother was having dengue without any symptoms ${ }^{2}$. Therefore it is important to consider the possibility of DF in newborns presenting with fever, above mentioned signs and reduced platelet counts.

It is known that re-infection with Dengue virus can lead to more severe complications. Hence, when a baby gets the initial infection inside the womb or as a newborn, they will be at risk of getting secondary dengue as infants or very young children. Parents should always safely keep the diagnosis cards/documentary proof of DF in their unborn or newborn babies, so that they can alert health staff if the child gets another subsequent attack of dengue.

Scientists have so far not found an antiviral medication against DF. An effective vaccine is currently unavailable. Therefore, prevention is still the most effective strategy. This can be achieved by eliminating vector breeding sites and measures to prevent mosquito bites.

The message to the parents is that even newborns can get Dengue Fever and Dengue Haemorrhagic Fever.

\section{References}

1. Weerasekera M, Sinhabahu VP, Ratnasiri KMSS. Dengue haemorrhagic fever in a neonate: red alert for neonatal care-givers. Sri Lanka Journal of Child Health 2015; 44(2):112-3.

https://doi.org/10.4038/sljch.v44i2.7993

2. Gamhewage NC, Weerasekera M, Nazmy MHM. Vertically transmitted dengue in a neonate born to a mother with asymptomatic dengue infection. Sri Lanka Journal of Child Health 2019; 48(2):168-9.

https://doi.org/10.4038/sljch.v48i2.8715 